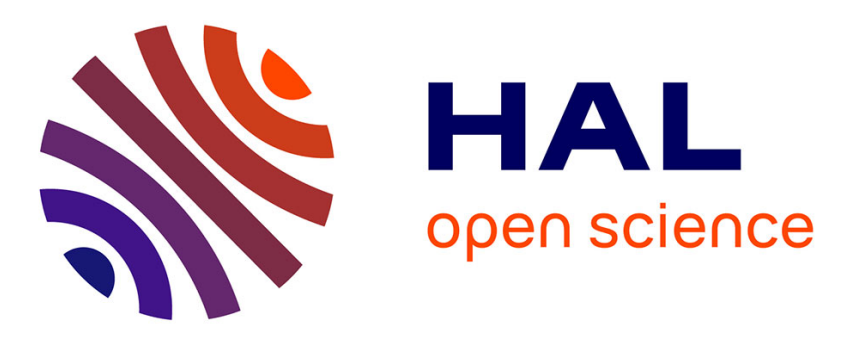

\title{
Migraine and Two-Pore-Domain Potassium Channels
}

Clément Verkest, Stephanie Häfner, Pablo Ávalos Prado, Anne Baron, Guillaume Sandoz, Pablo Ávalos Prado

\section{To cite this version:}

Clément Verkest, Stephanie Häfner, Pablo Ávalos Prado, Anne Baron, Guillaume Sandoz, et al.. Migraine and Two-Pore-Domain Potassium Channels. Neuroscientist, 2021, 27 (3), pp.268-284. 10.1177/1073858420940949. hal-03375321

\section{HAL Id: hal-03375321 \\ https://hal.science/hal-03375321}

Submitted on 12 Oct 2021

HAL is a multi-disciplinary open access archive for the deposit and dissemination of scientific research documents, whether they are published or not. The documents may come from teaching and research institutions in France or abroad, or from public or private research centers.
L'archive ouverte pluridisciplinaire $\mathbf{H A L}$, est destinée au dépôt et à la diffusion de documents scientifiques de niveau recherche, publiés ou non, émanant des établissements d'enseignement et de recherche français ou étrangers, des laboratoires publics ou privés. 


\section{Migraine}

2 and

\section{Two-Pore-Domain Potassium Channels}

4

5

6

7

8

9

10

11

12

13

14

15

16

17

18

19

20

21

22

23

24

Authors: Clément Verkest $1^{1,2,3^{*}}$, Stephanie Häfner ${ }^{1,2^{*}}$, Pablo Ávalos Prado ${ }^{1,2^{*}}$, Anne Baron $^{2,3}$, Guillaume Sandoz ${ }^{1,2 \#}$

\section{Affiliations :}

${ }^{1}$ Université Cote d'Azur, CNRS, INSERM, iBV, France.

${ }^{2}$ Laboratories of Excellence, Ion Channel Science and Therapeutics Nice, France.

${ }^{3}$ Université Cote d'Azur, CNRS, INSERM, Institut de Pharmacologie Moléculaire et Cellulaire, France

${ }^{*}$ Contribute equally for this work

\# Correspondence to: sandoz@unice.fr 
Migraine is a common, disabling neurological disorder with a genetic, environmental and hormonal component with an annual prevalence estimated at $\sim 15 \%$. It is characterized by attacks of severe, usually unilateral and throbbing headache, and can be accompanied by nausea, vomiting and photophobia. Migraine is clinically divided into two main subtypes: migraine with aura, when it is preceded by transient neurological disturbances due to cortical spreading depression (CSD), and migraine without aura. Activation and sensitization of trigeminal sensory neurons, leading to the release of pro-inflammatory peptides, is likely a key component in headache pain initiation and transmission in migraine. In the present review, we will focus on the function of Two-Pore-Domain potassium $\left(\mathrm{K}_{2 \mathrm{P}}\right)$ channels which control trigeminal sensory neuron excitability and their potential interest for developing new drugs to treat migraine.

Key words: Migraine, trigeminal sensory neurons, $\mathrm{K}_{2 \mathrm{P}}$ channels, $\mathrm{KCNK}$, heterodimerization, frameshift mutation-induced alternative translation initiation (fsATI), allodynia, Kozac sequence, excitability. 


\section{Introduction}

Migraine is one of the most common diseases world-wide, affecting nearly $15 \%$ of the global population, with a women to men ratio of 3:1. Its societal and economic burden is considerable (Burch and others 2015). Migraine manifests as a unilateral throbbing headache and is accompanied by multiple symptoms such as nausea, vomiting, photophobia, phonophobia or cutaneous allodynia. The migraine attack is often split into four different phases following a temporal pattern that can last for several days: premonitory, aura, headache and postdrome phase (Goadsby and others 2017) (Fig. 1). The premonitory phase can begin as early as three days before the headache and is characterized by fatigue, mood changes, food craving and yawning (Goadsby and others 2017). Around less than one third of patients will develop an aura before the headache, which consists of visual and sensory disturbances that will last from several minutes to a few hours. The underlying event is thought to be a cortical spreading depression (CSD), a wave of brief depolarization followed by a long-lasting depression of neuronal activity that propagates slowly in the brain (Charles and Baca 2013). Then, the headache phase will start, lasting between 4 to 72 hours. The migraine attack resolves with a postdrome phase, lasting from hours to days, and consisting of residual headache, fatigue and impaired cognitive functions (Bose and others 2018). In addition to the presence or not of aura, the frequency of headaches is used to further differentiate episodic migraine (headache with or without aura that occurs 1 to 14 days per month, for at least three months) or chronic migraine patients (at least 15 days of headache per month for at least three months) (Adams and others 2015). A broad array of symptoms contributes to the disability associated with migraine attacks and indicates involvement of brain regions in homeostatic, autonomic, emotional and sensory processing, thus highlighting a wide involvement of the nervous system in migraine (Vila-Pueyo 2018; Goadsby and others 2017). Imaging studies have confirmed that these non-pain symptoms and changes in the brain are not simply responses to pain but can exist in the absence of headache and produce functional imaging changes on their own (Denuelle and others 2007; Schulte and May 2016). Therefore, migraine can be considered as a broad sensory disorder. Migraine patients display abnormal responses toward pain (Nahman-Averbuch and others 2019) or light (Bernstein and others 2019). Other differences lie on responses that should be adaptive but become impaired or maladaptive, such as altered brainstem processing (Vila-Pueyo and others 2019), changes in gray matter volume (Coppola and others 2017), impaired adaptive cerebral hemodynamic mechanisms (Frederiksen and others 2019), habituation deficiency (Coppola and others 2005) or metabolic impairment (Gross and others 2019). Due to the nature of the triggers reported 
1 by patients (stress, sleep disorder etc.) (Karsan and Goadsby 2018; Turner and Houle 2018) and a clear involvement of the hypothalamus) in the early phases of the attack, migraine is considered as a deregulated response toward various stressful stimuli, highlighting the difficulty of the brain to keep a physiological and stable state. Thus, migraine has been described as a pathophysiology of allostasis (i.e. the responses that help to maintain physiological stability) (Borsook and others 2012). Despite the broad impact of migraine, the understanding of several aspects of its pathophysiology and underlying mechanisms remain unclear.

\section{Initiation of migraine attacks: triggering factors and genetic aspects}

\section{Triggering factors}

Among various external factors able to trigger migraine attacks, stress is the most reported (Turner and Houle 2018). In clinical and preclinical context, methods for inducing a migraine attack include the injection of triggering molecules, like the calcitonin gene-related peptide (CGRP), for which elevated levels have been measured in patients during migraine attacks (Edvinsson and others 2018), nitric oxide (NO) donors or pituitary adenylate-cyclase activating peptide (PACAP) (Al-Karagholi and others 2019; Ashina and others 2017b; Ashina and others 2017a; De Felice and others 2010; De Felice and Porreca, 2009; Guo and others 2016; Liu and others 2013). However, NO donors, for example, are triggers in migraine patients but poorly affect healthy volunteers (Schytz and others 2010). Nevertheless, in certain experimental conditions (doses and combined use of provocative drugs, duration of treatment), a higher proportion of healthy individuals may develop a genuine migraine attack, suggesting the existence of a putative "migraine threshold" (Olesen and Ashina 2015).

\section{Genetic aspects}

Early studies on the genetics of migraine have led to the identification of several genes responsible for rare cases of familial hemiplegic migraine (FHM). This includes FHM1, a gain-of-function mutation affecting the alpha subunit of the voltage-gated calcium channel $\mathrm{Ca}_{\mathrm{v}} 2.1$ (CACNA1A) leading to an increase in synaptic transmission (van den Maagdenberg and others 2004), FHM2, a loss-of-function mutation targeting the alpha 2 subunit of the astrocytic $\mathrm{Na}^{+} / \mathrm{K}^{+}$ATP-dependent pump (ATP1A2) and resulting in an impaired clearance of synaptic glutamate (De Fusco and others 2003) and FHM3, impairing the alpha subunit of the voltage-gated sodium channel $\mathrm{Na}_{\mathrm{v}} 1.1$ (SCN1A) (Dichgans and others 2005; Zerimech and others 2020). However, those mutations are also linked to other diseases such as dyskinesia, 
ataxia or mental retardation. Furthermore, they only account to a minor proportion of migraine patients (around 1 of 10000) (Ducros 2013). Another gene whose loss of function has been recently associated with migraine is KCNK18, which encodes the Two-PoreDomain $\left(\mathrm{K}_{2 \mathrm{P}}\right)$ potassium channel TRESK (Twik-related spinal cord $\mathrm{K}^{+}$channel) (Lafrenière and others 2010). The mutation in this gene was the only one which has been linked to a "common" migraine phenotype. Nevertheless, the latter was a matter of controversy until recently (Royal and others 2019; Pettingill and others 2019, see below).

Due to their contribution to neuronal excitability, a genomic study has explored the potential involvement of hundreds of ion transport genes in migraine pathology (Nyholt and others 2008). However, a significant gene variant has not been identified. In the last years, larger scale genome-wide association studies (GWAS) have made important contributions to identify genetic components involved in migraine, resulting in new hypotheses regarding migraine pathophysiology (Nyholt and others 2017). Further studies provided evidence that common types of migraine are genetically complex: multiple genetic variants with small effect sizes act together with environmental factors to confer migraine susceptibility (Gormley and others 2018). Interestingly, those studies have identified other variants in genes encoding $\mathrm{K}_{2 \mathrm{P}}$ channels, namely KCNK5 (TASK2, Twik-related acid sensing $\mathrm{K}^{+}$channel) (Gormley and others 2016) and KCNK4 (TRAAK, Twik-related arachidonic acid stimulated $\mathrm{K}^{+}$channel). It is also of note that migraine has a genetic overlap with psychiatric disorders, especially depression, in which $\mathrm{K}_{2 \mathrm{P}}$ channels have been also shown to play a role (Heurteaux and others, 2006; Djillani and others 2019).

\section{Anatomy - Focus on the migraine pain pathway}

Multiple sensory symptoms arise during a migraine attack, being the headache the most prominent one. It is now well established that migraine headache is the result of the activation and sensitization (decreasing response threshold and increasing response strengths) of trigeminal neurons and, to a lesser extent, cervical nociceptive $\mathrm{C}$ (non-myelinated) and $\mathrm{A} \delta$ (myelinated) fibers that innervate cranial meninges and their blood vessels (Khan and others 2019; Strassman and others 1996). This ensemble is commonly referred to the trigeminovascular system (Fig. 2). The pathway starts in trigeminal sensory neurons whose cell bodies are located in the trigeminal ganglia (TG) and send peripheral axons to the meningeal dura mater and the surrounding blood vessels through the ophthalmic branch of the trigeminal nerve (V1). Central axons from TG neurons project to the trigeminal nucleus caudalis (TNC) (Uddman and others 1985). This nucleus integrates signals from projections 
coming from periorbital skin and pericranial muscles. The ascending axon projections of TNC transmit nociceptive information to diverse hypothalamic, brainstem and basal ganglia nuclei that could explain different migraine related symptoms such as vomiting, nausea and yawning (Burstein and others 2015). Additionally, trigeminovascular nociceptive information is subject to extensive modulation by multiple descending neurons from different brain regions (Goadsby and others 2017), including various brainstem nuclei, notably the Locus coeruleus and Periaqueductal Grey (Edelmayer and others 2009; Vila-Pueyo and others 2019), the hypothalamus (Goadsby and others 2017) or the cerebral cortex (Noseda and others 2010).

Activation of trigeminal and innervating fibers in meninges is thought to initiate a neurogenic and sterile inflammation, owing to the dense population of various vasoactive neuropeptides (i.e. CGRP, PACAP and substance P) within sensory neurons and to the proximity of blood vessels, immune cells (Edvinsson and others 2018; Levy and others 2019; Rua and McGavern 2018) and autonomic neuron fibers (Harriott and Gold 2009). Meningeal sensory neurons are equipped with a rich set of receptors and ion channels, allowing them to be exquisitely sensitive and to respond to a broad range of chemical and mechanical stimuli (Burgos-Vega and others 2016; Levy and others 2019; Bonnet and others 2019). There is now growing evidence that an inflammatory component might sustain nociceptor activation and sensitization, through the action of protons, cytokines or neurotrophic factors and their downstream targets (van Dongen and others 2017).

However, the initiating event leading to the activation of meningeal sensory neurons in the context of a migraine attack remains unclear. Regarding migraine with aura, CSD was shown to activate meningeal nociceptors, being also linked to a meningeal inflammation (Bolay and others 2002; Karatas and others 2013; Hadjikhani and others 2020). A more likely explanation combines extensive modulation of trigeminovascular information, predetermined hyperexcitable migraine brain and increase of nociceptive information by external triggering factors (Kunkler and others 2018; Bree and Levy 2018). Nowadays, it is well-established that trigeminal neuron hyperexcitability is a key factor for migraine headache generation and some associated symptoms (throbbing headache, cutaneous allodynia, some autonomic symptoms) through its role in the development of peripheral and central sensitization at various levels of the migraine pain network (Strassman and others 1996; Olesen and others 2009).

\section{$\mathrm{K}_{2 \mathrm{P}}$ channels and pain}

$\mathrm{K}_{2 \mathrm{P}}$ channels constitute one of the major families of $\mathrm{K}^{+}$channels. Its members share a dimeric structure with four transmembrane domains and two pore loops per subunit. Because 
1 of the two pore loops per subunit, these channels are not active as tetramer but as dimer (Fig.

2 3). $\mathrm{K}_{2 \mathrm{P}}$ channels exhibit a "background" $\mathrm{K}^{+}$conductance that is time- and voltageindependent and brings the resting membrane potential of cells toward the $\mathrm{K}^{+}$potential equilibrium. Therefore, they serve as a hub for the regulation of neuronal excitability by setting the resting membrane potential below the firing threshold in excitable cells. Furthermore, they were recently shown to contribute to neuronal high firing frequency and high-speed conduction along myelinated axons by driving action potential repolarization (Brohawn and others 2019; Kanda and others 2019; Ávalos Prado and Sandoz 2019). 15 genes have been found to encode for this channel family that can be subdivided into six subfamilies depending of their sequence homology and biophysical properties (Box 1). $\mathrm{K}_{2 \mathrm{P}}$ channels play a central and active role in the response of cells to extracellular and intracellular signals as diverse as G-Protein Coupled Receptor (GPCR) signaling, $\mathrm{pH}$ and membrane stretch. They have been shown to participate in multiple physiological and pathological aspects of peripheral pain perception. Notably, they have been implicated in thermal and mechanical nociception (Fig. 4, Noël and others 2009) and also in inflammatory, neuropathic, cancer, and recently, migraine pain (Alloui and others 2006; Descoeur and others 2011; Lafrenière and others 2010). This group mainly includes TWIK1, the members of the TREK subfamily (TREK1, TREK2 and TRAAK), the TASK subfamily members (TASK1 and TASK3) and TRESK (Li and Toyoda 2015). They are all expressed throughout the nervous system along the pain pathway in various populations of dorsal root ganglia (DRG) or TG sensory neurons. It is worth to note that they are enriched in small and unmyelinated neurons that are mainly involved in noxious stimuli detection (e.g. peptidergic, non-peptidergic, itch or cold-sensitive) (Acosta and others 2014; Alloui and others 2006; Pereira and others 2014).

\section{$\mathrm{K}_{2 \mathrm{p}}$ channels and migraine}

With the identification of the FHM genes in the late 90s and in the mid-2000s, a subsequent large-scale study was conducted by Nyholt and colleagues investigating the potential contribution to migraine pathology of common variations affecting several ion transport-related genes. Though none of the studied variants reached a statistical threshold, two $\mathrm{K}_{2 \mathrm{P}}$ channels (TREK1 and THIK2) were preliminarily selected as promising candidates in a Finnish cohort (Nyholt and others 2008). A pioneer study clearly linking $\mathrm{K}_{2 \mathrm{P}}$ channels and migraine led to the identification of a frameshift mutation in the gene encoding for TRESK channel, the F139WfsX24 mutation (TRESK-MT). This mutation, segregating perfectly with migraine with aura phenotype (and sometime without aura), was shown to 
produce a non-functional protein that served as a dominant-negative form of the wild-type

2 (WT) TRESK channel (Lafrenière and others 2010) explaining its genetic dominant role.

3 TRESK-MT has been shown to induce hyperexcitability of TG neurons (Liu and others 2013;

4 Guo and others 2014), which likely underscores its role in migraine. Furthermore, the causative role of this mutation was emphasized by an elegant study with human nociceptive neurons derived from induced pluripotent stem cells from migraine patients. In fact, these neurons are hyperexcitable and CRISPR-Cas9 engineering, for correcting the F139WfsX24 mutation, reversed the neuronal hyperexcitability (Pettingill and others 2019). However, in a subsequent genetic screening study, another missense TRESK variant, C110R, was identified (Andres-Enguix and others 2012). The TRESK-C110R mutation, similarly to TRESK-MT, was shown to produce a non-functional channel which exerts a dominant negative effect on the WT-TRESK channel in heterologous cells, but unexpectedly this mutant was found to have no effect on TG excitability when overexpressed (Guo and others 2014) and in human derived C110R mutant neurons (Pettingill and others 2019). This absence of effect elucidates why this mutant was found in both migraine and control subjects. We have recently shown in rodent that, even though both mutations lead to the same apparent deleterious effect on TRESK function, only TRESK-MT is able to functionally inhibit two other members of the $\mathrm{K}_{2 \mathrm{P}}$ channel family (Fig. 5). Inhibition of TREK1 and TREK2 channels activity then induces TG hyperexcitability and subsequent migraine pathophysiology (Fig. 6) (Royal and others 2019; see below).

\section{$K_{2 P}$ channels, heteromerization and $T G$ excitability}

Even though $\mathrm{K}_{2 \mathrm{P}}$ channels share a low level of sequence identity, it has been recently shown that heteromerization is not rare between $\mathrm{K}_{2 \mathrm{P}}$ members, increasing functional diversity (Levitz and others 2016, Blin and others 2016). Heteroassembly can occur within the same subfamily but also between different subfamily members, as was shown for the dimerization of TRESK with TREK1 and TREK2 in TG neurons (Royal and others 2019). The question, why only TRESK-MT, and not TRESK-C110R leads to an inhibition of TREK1 and TREK2, was solved by the discovery of a new mechanism allowing transmission of inherited diseases through an alternative translation initiation induced by a frameshift mutation in TRESK-MT called frameshift mutation induced Alternative Translation Initiation (fsATI, Box 2; Royal and others 2019). 
The TRESK-MT mutation leads, through fsATI, to the production of two protein fragments instead of one, as expected (Box 1): TRESK-MT1, which corresponds to the expected C-terminal truncated TRESK channel and inhibits TRESK, and TRESK-MT2, which corresponds to an N-terminal truncated TRESK channel. TRESK-MT2, by coassembling and inhibiting TREK1 and TREK2, induces TG sensory neuron hyperexcitability (Fig. 5). Overexpression of TRESK-MT2 in rat TG neurons, using virus, is sufficient to induce a chronic facial mechanical allodynia related to chronic migraine, an effect which has not been seen with MT1 (Royal and others 2019). Interestingly, fsATI was also found for another TRESK mutant (Y121LfsX44), which is the only other TRESK mutation related to migraine in human (Royal and others 2019; Domitrz and others 2016; Rainero and others 2014). This mutation also leads to the production of a similar TRESK-MT2 (Royal and others 2019). The fundamental role of TREK1 and TREK2 in migraine induction has been further supported by TREK1/TREK2 double knock-out (KO) mice (Fig. 5). They exhibit a chronic migraine-like cutaneous mechanical allodynia phenotype which can be reversed by Topiramate, a drug used in clinic to treat migraine (Royal and others 2019). This suggests, that, in human, migraine is due to the dysfunction of TREK1 and TREK2 and their respective heteromers with mutated TRESK, but not due to TRESK invalidation alone (Fig. 6).

In parallel, other preclinical studies in rodents have further confirmed a key involvement of $\mathrm{K}_{2 \mathrm{P}}$ channels in trigeminal nociception and migraine-related headache. Recently, TRESK invalidation was shown to increase peptidergic trigeminal neurons excitability (Guo and others 2019) and to enhance headache behavior induced by application of inflammatory mediators in the meninges (Pettingill and others 2019). These results would favor that TRESK is sufficient to generate migraine. Nevertheless, the finding by Guo and others. and Pettingill and others. also fits with TREK1 and TREK2 implication. In fact, by only targeting TRESK, TRESK-MT1 and C110R, the sensory neuron excitability is not altered (Pettingill and others 2019; Guo and others 2014; Royal and others 2019), whereas genetic invalidation affects TRESK homodimers as well as heterodimers (TRESK-TREK1, TRESK-TREK2) and therefore also TREK1 and TREK2 expression and composition at the cell surface (the equilibrium is modified). These differences between gene invalidation and dominant negative (affecting only TRESK) may explain why TRESK invalidation modifies TG excitability and induces a migraine phenotype. All in all, migraine-like behavior in rodents seems to involve both TRESK, TREK1 and TREK2 monomeric channels and TRESK-TREK heterodimeric channels. 
Finally, in addition to these channels, TASK3 is also predominant in TG neurons, where it co-localizes with TRESK, TREK1 and TREK2 (Yamamoto and others 2009). Nevertheless, there is no evidence of TASK3 participation in migraine attacks. It is worth to mention, that TASK3 was not found to heteromerize with TRESK, TREK1 and TREK2 (Levitz and others 2016; Royal and others 2019).

\section{Toward new treatments for migraine involving $\mathrm{K}_{2 \mathrm{p}}$ channels targeting}

Migraine therapy aims to terminate or to relief acute attacks, but also to prevent the evolution from episodic toward chronic migraine. Several drugs are used but present several side effects (Table1 and 2), for example, Topiramate may be used to treat chronic migraine but it has severe well-known side effects including ataxia, confusion, diplopia, dizziness, drowsiness, dysphasia, fatigue, memory impairment and others. Given the importance of CGRP as a migraine trigger, the use of monoclonal antibodies against this peptide represents one of the most effective treatments against the disease. Up to now, three different humanized monoclonal antibodies against CGRP pathway have been tested and exhibited excellent results: Fremanezumab and Galcanezumab, which target CGPR, and Erenumab, which targets CGRP receptors (Fig. 7). All three products have demonstrated efficacy for the preventive treatment of chronic and episodic migraine and can be periodically self-administered (Spindler and Ryan 2020). In addition, they support the fact that an intervention at the level of the peripheral nervous system is sufficient to target migraine headache. Nevertheless, general side effects caused by monoclonal antibody drugs cannot be excluded such as flu-like symptoms and allergic reactions in addition to the "specific" side effects such as dizziness, joint pain or pruritus and erythema.

Given their abundant expression in DRG, TG sensory and primary afferent neurons, drugs targeting $\mathrm{K}_{2 \mathrm{P}}$ channels constitute a promising therapy for the treatment of migraine and its associated pain, but also of inflammatory, neuropathic or cancer pains (Pereira and others 2014; Noël and others 2009; Alloui and others 2006; Descoeur and others 2011). This idea is strengthened by the fact that $\mathrm{K}_{2 \mathrm{P}}$ channels have been shown to be involved in other diseases such as depression (Heurteaux and others 2006) which severely affect $10 \%$ of the population suffering from migraine disorders, and that some drugs targeting $\mathrm{K}_{2 \mathrm{P}}$ channels have been proved to be effective against migraine, such as cloxyquin through TRESK activation (Pettingill and others 2019). 
As previously shown, at least three $\mathrm{K}_{2 \mathrm{P}}$ channels subunits and their respective 2 heteromers have been proved to be involved in the normal physiology and pathophysiology of migraine. TRESK, TREK1 and TREK2 containing channels seem to serve as a hub to set the negative resting potential of TG neurons (Dobler and others 2007; Lafrenière and others 2010; Royal and others 2019). Thus, specific pharmacology targeting these channels should be potentially relevant for the development of anti-migraine treatment. Furthermore, targeting heterodimers would allow to reach higher specificity. Currently, only a small number of agonists of the aforementioned channels have been studied to be effective for migraine treatment. Among them, the anti-leukotriene agent Montelukast for asthma management has been demonstrated to act as a well-tolerated and prophylactic agent against acute migraine episodes at 10-20 mg dose per day (Sheftell and others 2000). Its efficacy may lie in its ability to specifically activate TRESK and TRESK heteromer channels (Wright and others 2019).

During migraine, experimental studies have demonstrated an increase of prostaglandin 2 (PGE2) in the trigeminovascular system, where their receptors are distributed along TG and TNC neurons and induce vasodilation of cranial vessels (Antonova and others 2013). PGE2 is also known to be a potent inhibitor of TREK1 channels (Honoré 2007). Non-steroidal antiinflammatory drugs (NSAIDs), which represent another widespread treatment to manage headache in acute migraine, may eventually avoid TREK1 inhibition.

Finally, although they have not yet been clinically tested, a number of selective activators of $\mathrm{K}_{2 \mathrm{P}}$ channels should also be considered for chronic migraine prevention. Among them, it is worth to mention ML67-33, a well-known specific activator of TREK1, TREK2 and TRAAK channels, that exhibit an $\mathrm{EC}_{50}$ in micromolar range (Bagriantsev and others 2013). Further development of selective agents targeting specific heterodimers involving TRESK may be considered to increase specificity and to reduce secondary drug effects.

\section{Concluding remarks}

Migraine is a common and disabling disease associated with disorders in neuronal excitability and cerebral blood flow. The complexity of the underlying processes which are not yet fully understood still render migraine treatment difficult. Currently, it is assumed that migraine headache is triggered by TG neuron activation. Hyperexcitability of TG fibers evokes release of vasoactive neuropeptides that enhance vasodilation causing neurogenic inflammation. This leads to a pain response to be conveyed to higher brain centers including cortex, hypothalamic, brainstem and basal ganglia nuclei. The mechanisms leading to trigeminal hyperexcitability have not been fully elucidated until very recently. 
$\mathrm{K}_{2 \mathrm{P}}$ channels, namely homo- and heterodimers of TRESK, TREK1 and TREK2, seem

2 to play a key role in TG neuronal excitability and are therefore promising targets for migraine 3 treatment. The discovery of a new type of translation initiation, generating several protein 4 forms that can regulate other channels by heteromerization, clarified the understanding of $\mathrm{K}_{2 \mathrm{P}}$ 5 channel implication in this disease. Henceforth, the novel role of $\mathrm{K}_{2 \mathrm{P}}$ channels in migraine, as 6 well as their ability to generate functional and non-functional heterodimers, provides 7 motivation for developing a deeper understanding of their function and organization within 8 the plasma membrane and demonstrates that they have to be now taken into consideration for 9 the development of highly specific pharmacological agents to treat migraine.

\section{Funding}

12 This work was supported by a grant to G.S. by the Fondation pour la Recherche Medicale (Equipe labellisée FRM 2017, FRM DEQ20170336753 and ANR AT2R-TRAAKBioanalgesics ANR-17-CE18-0001) as well as Laboratory of Excellence "Ion Channel Science and Therapeutics," grant ANR-11-LABX-0015-01 and the French government, through the UCAJEDI Investments in the Future project managed by the National Research Agency (ANR) with the reference number ANR-15-IDEX-01. The work was also supported by a grant to P.A.P. by the Fondation pour la Recherche Medicale (FRM 2019, FDT201904008083). 


\begin{tabular}{|c|c|c|}
\hline Preventive treatment & Targets & Mechanism of action \\
\hline $\begin{array}{l}\text { Beta blockers } \\
\text { (Propranolol) }\end{array}$ & $\beta 1-2$ receptor antagonist & $\begin{array}{c}\text { Stress reduction, neuronal } \\
\text { modulation (descending } \\
\text { controls), vascular effects? }\end{array}$ \\
\hline \multirow{5}{*}{$\begin{array}{l}\text { Antiepileptics } \\
\text { (Valproate, } \\
\text { Topiramate, } \\
\text { Levetiracetam, } \\
\text { Flunarizine, } \\
\text { Gabapentine) }\end{array}$} & Valproate: $\mathrm{Na}_{\mathrm{v}}$ antagonist & $\begin{array}{l}\text { Decrease in neuronal } \\
\text { excitation }\end{array}$ \\
\hline & $\begin{array}{l}\text { Topiramate: acts on } \mathrm{Na}_{\mathrm{v}}, \mathrm{Ca}_{\mathrm{v}} \text { and } \\
\text { carbonic anhydrase, modulates } \\
\text { GABA-A and kainate receptors }\end{array}$ & $\begin{array}{l}\text { Decrease in neuronal } \\
\quad \text { excitation }\end{array}$ \\
\hline & $\begin{array}{l}\text { Levetiracetam: acts on SV2A } \\
\quad \text { (vesicular protein), } \mathrm{Ca}_{\mathrm{v}}\end{array}$ & $\begin{array}{c}\text { Decrease in neuronal } \\
\text { excitation, modulation of } \\
\text { neuronal activity }\end{array}$ \\
\hline & $\begin{array}{l}\text { Flunarizine: calmodulin blocker, } \\
\text { H1R, 5HTR and D2R antagonist }\end{array}$ & $\begin{array}{l}\text { Reduces neuronal excitation, } \\
\text { modulation of neuronal } \\
\text { activity? }\end{array}$ \\
\hline & Gabapentine: $\mathrm{Ca}_{\mathrm{v}}(\alpha 2 \delta)$ antagonist & Reduces neuronal excitation \\
\hline \multirow{2}{*}{$\begin{array}{c}\text { Antidepressors } \\
\text { (tricyclic: } \\
\text { Amitriptyline, SNRIs: } \\
\text { Venlafaxine) }\end{array}$} & $\begin{array}{c}\text { Amitriptyline: prevents } \\
\text { monoamine reuptake, multiple } \\
\text { potential secondary targets (5HTR, } \\
\mathrm{H} 1-2 \mathrm{R}, \alpha 1 \mathrm{R}, \mathrm{Ca}_{\mathrm{v}}, \mathrm{Na}_{\mathrm{v}}, \mathrm{K}_{\mathrm{v}} \text { etc.) }\end{array}$ & $\begin{array}{c}\text { Multiple actions: Decrease in } \\
\text { neuronal excitation, } \\
\text { modulation of neuronal } \\
\text { activity } \\
\end{array}$ \\
\hline & $\begin{array}{l}\text { Venlafaxine: prevents monoamine } \\
\text { reuptake }\end{array}$ & $\begin{array}{l}\text { Modulation of neuronal } \\
\text { activity? }\end{array}$ \\
\hline $\begin{array}{l}\text { 5HTR antagonists } \\
\text { (Pizotifen, } \\
\text { Methysergide) } \\
\end{array}$ & 5HT2R antagonists & $\begin{array}{c}\text { Modulation of neuronal } \\
\text { activity? }\end{array}$ \\
\hline Botulinum toxin & $\begin{array}{c}\text { Exocytosis of neurotransmitter } \\
\text { vesicle }\end{array}$ & $\begin{array}{c}\text { Multiple actions: muscle } \\
\text { contraction, neuronal } \\
\text { modulation (TRP trafficking, } \\
\text { synaptic transmission)? } \\
\end{array}$ \\
\hline \multirow[b]{2}{*}{$\begin{array}{l}\text { ACE inhibitors } \\
\text { (Lisinopril, } \\
\text { Candesartan) }\end{array}$} & $\begin{array}{l}\text { Lisinopril: ACE blocker (reduces } \\
\text { production of angiotensine II) }\end{array}$ & \multirow[b]{2}{*}{$\begin{array}{l}\text { Multiple actions: Modulation } \\
\text { of neuronal activity } \\
\text { (autonomic and sensory), } \\
\text { vascular? }\end{array}$} \\
\hline & Candesartan: AT1R antagonist & \\
\hline $\begin{array}{c}\text { Anti-CGRP } \\
\text { (Erenumab, } \\
\text { Fremanezumab) }\end{array}$ & $\begin{array}{l}\text { Erenumab: antibody directed } \\
\text { against CGRP receptor }\end{array}$ & $\begin{array}{c}\text { Modulation of neuronal } \\
\text { function (neurotransmission, } \\
\text { neuromodulation) }\end{array}$ \\
\hline
\end{tabular}


Fremanezumab: antibody against CGRP peptide

3 Table 2. Current treatments of acute migraine, their targets and the proposed mechanism of action.

\begin{tabular}{|c|c|c|}
\hline Acute treatment & Targets & Mechanism of action \\
\hline \multirow{2}{*}{$\begin{array}{l}\text { First line analgesics } \\
\text { (Paracetamol, NSAID) }\end{array}$} & $\begin{array}{l}\text { Paracetamol: multiple targets } \\
\text { (modulation of } \mathrm{K}_{\mathrm{v}} 7 \text {, TRPV } 1 \text {, } \\
\mathrm{Ca}_{\mathrm{v}} 3.2, \text { COXs...) }\end{array}$ & $\begin{array}{c}\text { Multiple actions: Decrease in } \\
\text { neuronal excitation, } \\
\text { modulation of neuronal } \\
\text { activity? }\end{array}$ \\
\hline & NSAID: inhibition COXs & $\begin{array}{l}\text { Reduction of the production of } \\
\text { inflammatory molecules } \\
\text { (prostaglandines etc.) }\end{array}$ \\
\hline Triptans (Sumatriptan) & 5HT1B/5HT1D agonists & $\begin{array}{c}\text { Modulation of neuronal } \\
\text { function, other cells (vascular } \\
\text { for 5HT1B)? }\end{array}$ \\
\hline Dihydroergotamine & 5HT1B/5HT1D agonists & $\begin{array}{l}\text { Like Triptans, with a potential } \\
\text { central and vascular action }\end{array}$ \\
\hline $\begin{array}{l}\text { CGRP antagonists } \\
\text { (Rimegepant, } \\
\text { Ubrogepant) }\end{array}$ & CGRP receptor antagonist & $\begin{array}{c}\text { Modulation of neuronal } \\
\text { function (neurotransmission, } \\
\text { neuromodulation) }\end{array}$ \\
\hline Ditans (Lasmiditan) & 5HT1F/5HT1D agonist & $\begin{array}{c}\text { Modulation of neuronal } \\
\text { function (neurotransmission, } \\
\text { neuromodulation) }\end{array}$ \\
\hline
\end{tabular}




\section{Box I - Ion channel heteromerization and means to study it}

Heteromultimerization is a classical mechanism commonly used to increase the diversity of protein complexes. Despite the fact that $\mathrm{K}_{2 \mathrm{P}}$ channels share rather low sequence identity, it has been demonstrated that heteromerization is possible between different $\mathrm{K}_{2 \mathrm{P}}$ members. The first hints that pointed to the general possibility of a heteroassembly of $\mathrm{K}_{2 \mathrm{P}}$ members were reported in 2002 (Czirják and Enyedi 2002) when co-expression of TASK1 and TASK3 in Xenopus oocytes led to functional channels with intermediate channel properties. After, the existence of native TASK1/TASK3 dimers was proven in mammalian motoneurons (Berg and others 2004). Later, it was shown that these channels also dimerize with a member of a different subfamily, namely TWIK1 (Plant and others 2012), and several studies reported potential dimers of TWIK1/TREK1 (Mi Hwang and others 2014), THIK1/THIK2 (Blin and others 2014), TREK1/TREK2/TRAAK (Blin and others 2016; Levitz and others 2016), TASK1/TALK2 (Suzuki and others 2017) and finally, TREK1/TREK2/TRESK (Royal and others 2019). Nevertheless, not all $\mathrm{K}_{2 \mathrm{P}}$ subunits of the $\mathrm{K}_{2 \mathrm{P}}$ family are able to dimerize to form functional channels, but the compilation of a full $\mathrm{K}_{2 \mathrm{P}}$ interactome is impeded by the great variety of channel properties as well as the absence of specific pharmacology. The toolbox to study $\mathrm{K}_{2 \mathrm{P}}$ channel dimerization ranges from electrophysiology recordings of co-expressed or tandem-linked channels to fluorescence resonance energy transfer (FRET) assays or fluorescence imaging of co-localization experiments. The use of such various technical approaches has led to controversies in the field, for example for the TREK1-TWIK1 dimers, which has been described as the main potassium conductance in astrocytes (Hwang and others 2014), whereas this dimer was shown not to exist in a previous study (Plant 2012). To address the question of protein assembly, a new technology allowing direct visualization at single molecule level has been developed, the so-called Single Molecule Pulldown (SiMPull) assay (Jain and others 2011), based on antibody-mediated immunoprecipitation of protein subunits carrying an affinity tag (e.g. HA) on passivated coverslips (Fig. B1-1). These proteins serve as bait molecules which can capture their respective fluorescence tagged protein partners. The visualization of this interaction is then carried out by total internal fluorescence (TIRF) microscopy. The combination of biochemical immunoprecipitation with single molecule fluorescence microscopy allows to systematically test all $\mathrm{K}_{2 \mathrm{P}}$ interactions among the 120 that can be expected from the combination of the 15 members of the $\mathrm{K}_{2 \mathrm{P}}$ channel family (Fig. B1-2). 
A Expression

Protein1-GFP + HA-Protein2

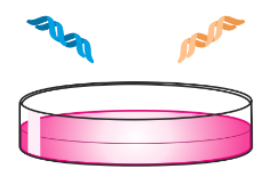

B

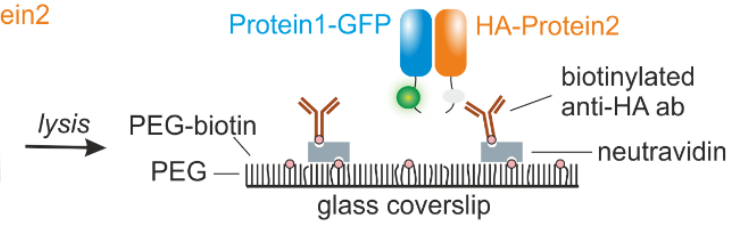

1

2 Figure B1-1: Principle of the Single Molecule Pulldown assay. (A) To study the interaction of

$4(G F P)$ is co-expressed with a second protein exhibiting an affinity tag like HA. (B) After lysis

5 of the cells, the lysate is applied in flow chambers on passivated coverslips containing surface

6 tethered antibodies. (C) The presence of GFP-tagged proteins allows the visualization of

7 single protein complexes by TIRF microscopy and subunit counting by observation of

8 bleaching events.

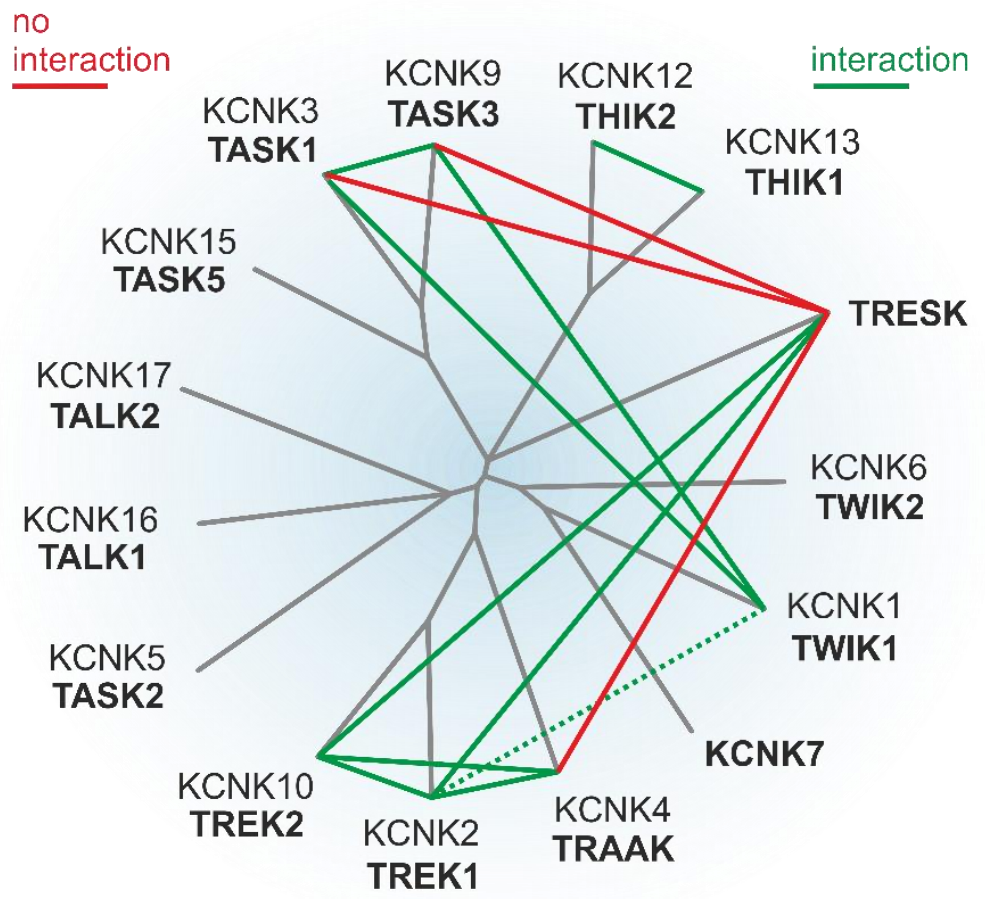

9

Figure B1-2: Interactome study of $K_{2 P}$ channels in $T G$ neurons. Green lines indicate a confirmed interaction between the respective subunits, while red lines connect subunits which are not interacting. The dotted line indicates the controversial interaction between TREK1 and TWIK1. 


\section{Box 2 - Frameshift-mutation induced alternative translation initiation}

The TRESK-MT mutation, induced by the frameshift F139WfsX24, is expected to encode for a non-functional channel, as it is truncated by its C-terminal part. The WT-TRESK channel was shown to interact with TREK1 and TREK2 in SiMPull assays, whereas the TRESK-MT channel was not (Royal and others 2019). If the inhibition of the TREK1/2 current by co-expression of TRESK-MT had not its origin in a co-assembly with this truncated channel form, there must be another explanation.

It has been assumed for a long time that one eukaryotic mRNA leads to the production of one single protein and that the variety of protein isoforms derived from one gene is evoked by alternative splicing or transcription from alternative promoters. The dogma of the existence of a unique translation start site was rebutted by Marilyn Kozak, who described that in certain cases, the rule of one mRNA - one protein is not followed as strictly (Kozak 1999). In fact, ribosomes can recognize an alternative initiation site and induce the generation of a second protein coming from the same RNA.

The canonical translation usually starts by binding of the $40 \mathrm{~S}$ ribosomal subunit, initiator tRNA and several initiating factors (e.g. elF4E) at the 5' cap structure, a 7methylguanosine $\left(\mathrm{m}^{7} \mathrm{G}\right)$ which precedes all eukaryotic mRNAs. The formation of this socalled pre-initiation complex is followed by linear scanning of the mRNA for an AUG initiation codon that is located in the right context which is in most eukaryotic mRNAs given by the Kozak sequence (A/G-XX-ATGG (Kozak 1987). Subsequent binding of the 60S ribosomal subunit to the translation initiation site (TIS) then initiates the protein translation. However, if the context of the first AUG on the mRNA is not optimal (i.e. not fully matching the Kozak sequence), the codon might be skipped, and the translation will start at a downstream AUG which has a more optimal context. This mechanism is also referred to as leaky scanning (Kochetov, 2008).

Such mechanism increases the diversity of proteins derived from one gene and has been already nicely described for $\mathrm{K}_{2 \mathrm{P}}$ channels in 2008 (Thomas and others 2008). In this study, an alternative translation initiation site in the TREK1 channel expressed in rat brain has been found to lead to a second truncated channel isoform missing the first 56 amino acids. This $\Delta 1-56$ TREK1 channel is able to form functional homodimers as pseudo-heterodimers with the full-length protein which leads to various channel isoforms with alternate open probability, conductance and permeability properties. Here, the second AUG was embedded 

effectively contribute to the regulation of CNS excitability.

A Canonical linear scanning

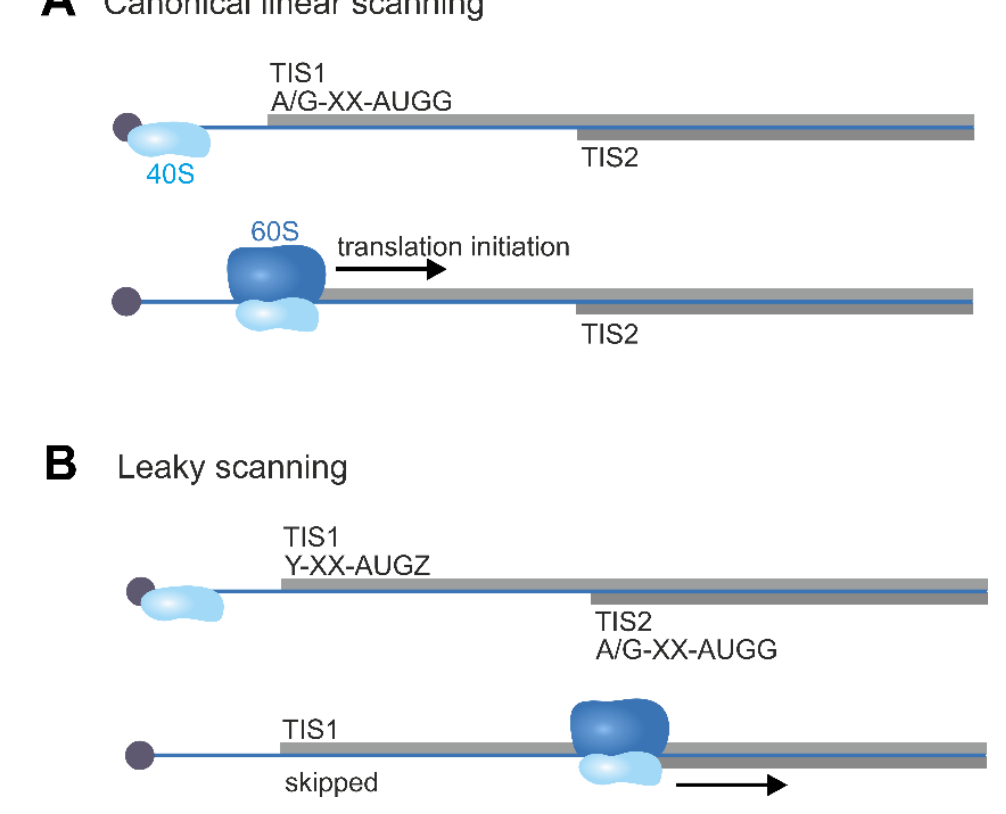

B Leaky scanning

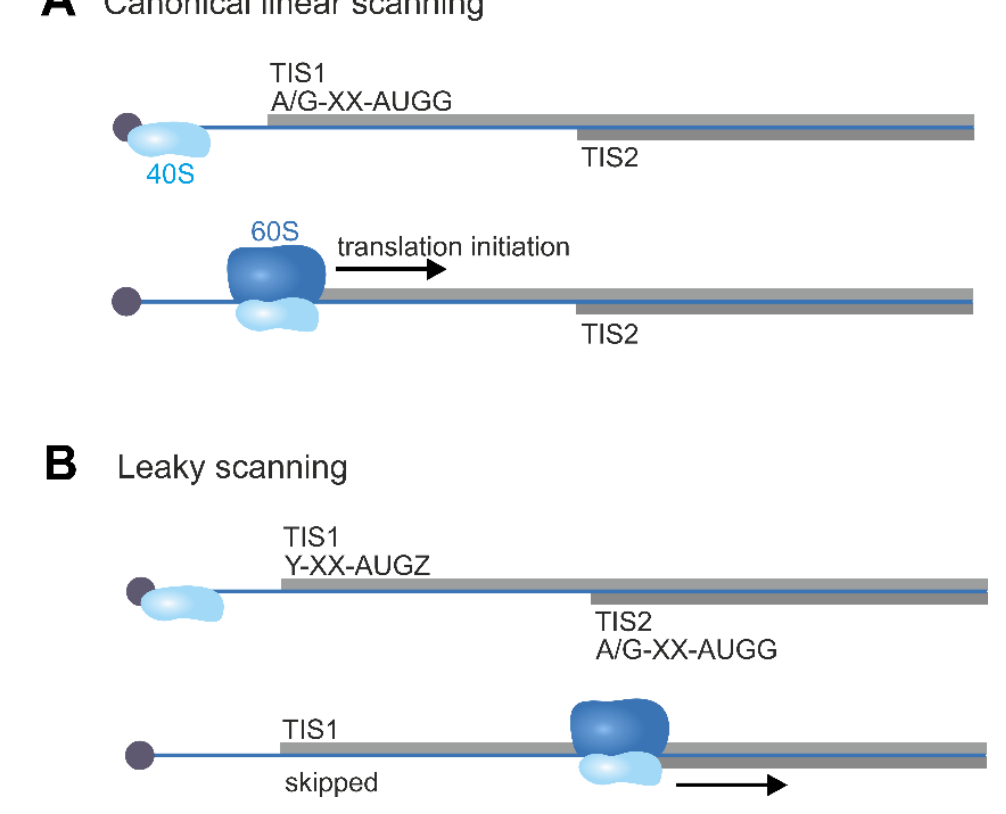

in a stronger Kozak sequence which is recognized more efficiently as the first AUG. The study impressively demonstrated, how leaky scanning of ion channel genes like KCNK2 can

Figure B2-1: Two common examples of eukaryotic translation initiation. (A) In the linear scanning model, the $40 S$ ribosomal subunit binds to the $5^{\prime} \mathrm{m}^{7} \mathrm{G}$ cap followed by subsequent scanning of the mRNA for an AUG codon, ideally embedded in a Kozak sequence $(A / G-X X$ AUGG), which serves as TIS. After assembly with the 60S ribosomal subunit, translation is initiated. (B) If the first scanned AUG is embedded in a suboptimal Kozak sequence ( $Y-X X$ AUGZ, $Y$ and $Z$ representing Kozak-deviant bases), it is not efficiently recognized, and the scanning will proceed until the next suitable TIS is detected.

In the case of the KCNK18 gene encoding for TRESK, a second AUG in a strong Kozak context can be found at position +356 , yet ahead of a very short open-reading frame (ORF2). The frameshift in TRESK-MT, which is induced by deletion of two base pairs (c.410_411delCT), puts the AUG of ORF2 in frame with the C-terminal part of the full length TRESK. As the AUG of ORF2 is also embedded in an environment matching the Kozak sequence, the frameshift leads to the efficient translation of a second protein that corresponds to a TRESK-channel truncated by its N-terminus and therefore, non-functional (TRESKMT2). The existence of this second transcript was elicited by several cell biological and biochemical assays (Royal and others 2019). We named the newly described mechanism, which is inducing an alternative translation site by displacing the open reading frame, fsATI (frameshift-mutation induced alternative translation initiation). 
A TRESK
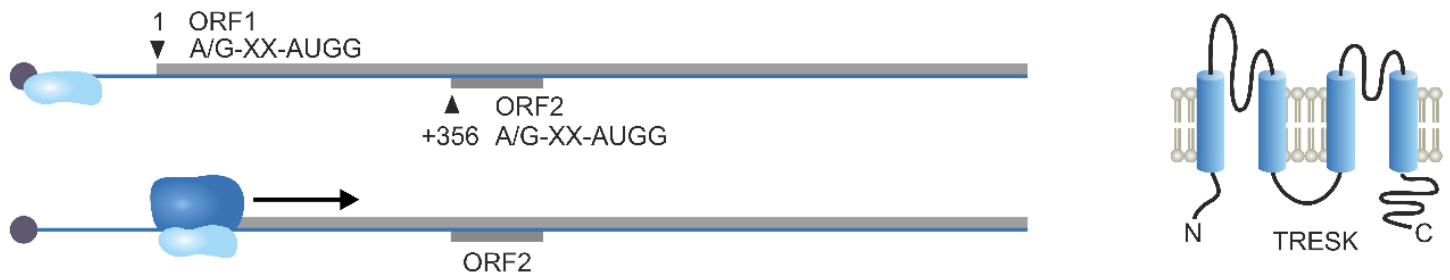

B F139WfsX24 (TRESK-MT)
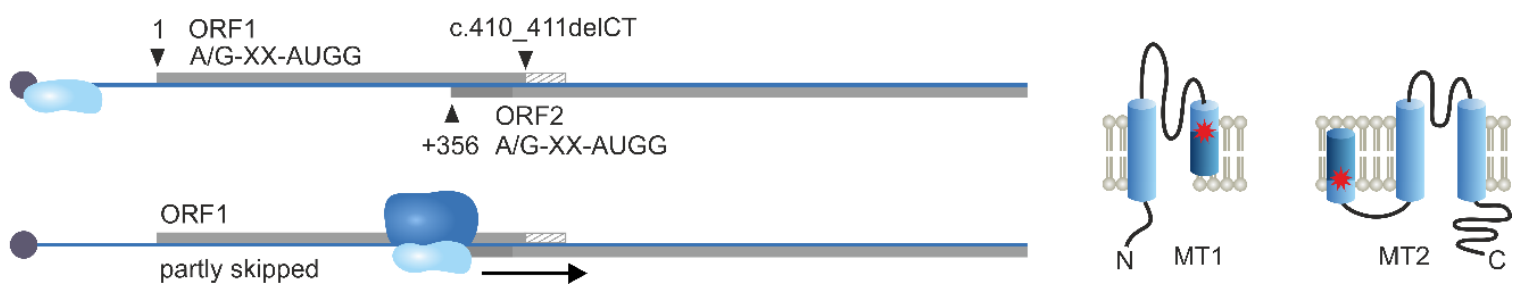

2 Figure B2-2: Principle of the frameshift-induced alternative translation initiation. (A)

3 Organization of ORF1 and ORF2 on mRNA of WT-TRESK. (B) The deletion of two base pairs

4 by the c.410_411delCT mutation results to a premature translation stop in ORF1(TRESK-

5 MT1). Coincidentally, the start codon of ORF2 at +356 is put in frame with the ORF of

6 TRESK, inducing the translation of MT2. 


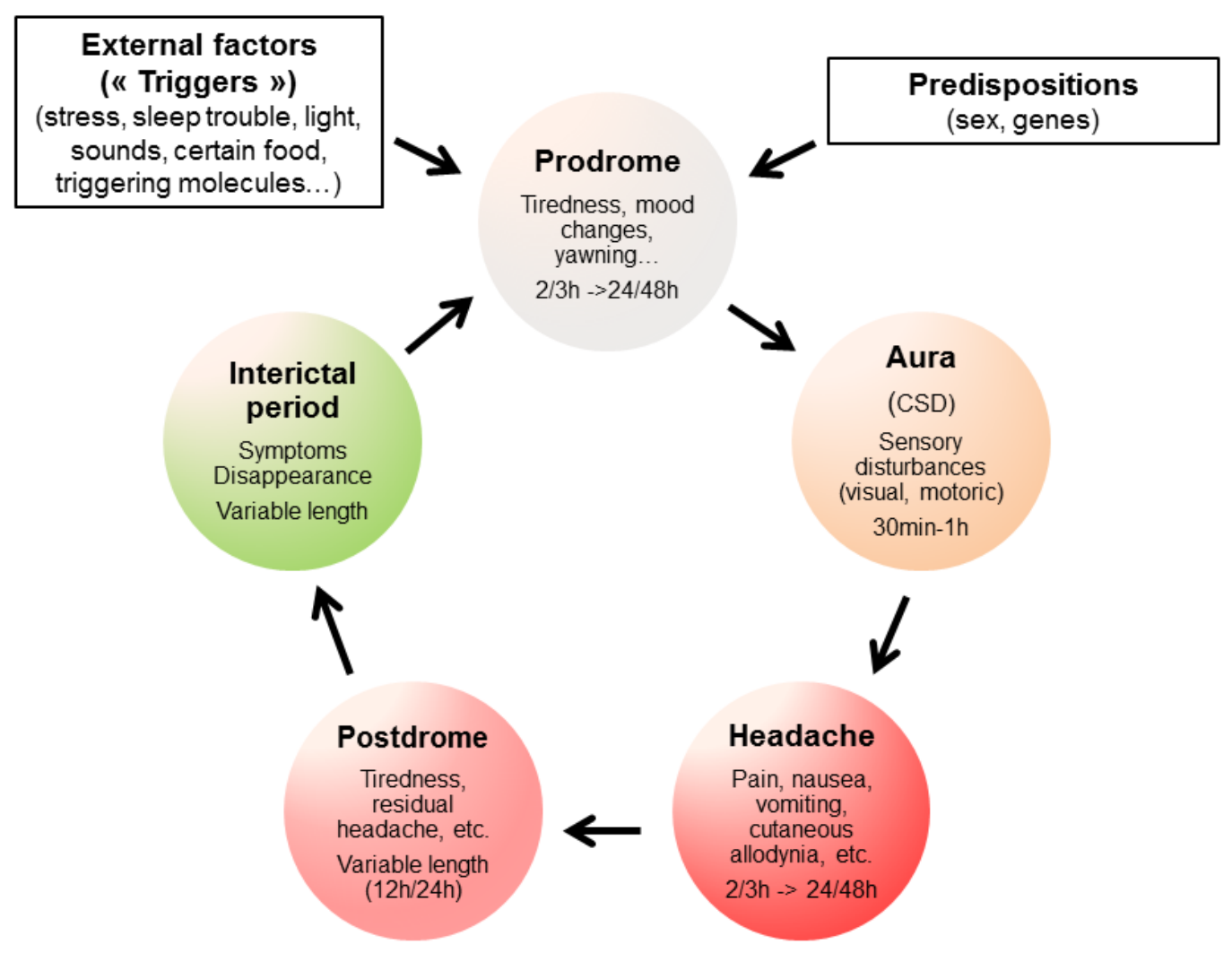

3 Figure 1. Schematic display of the migraine crisis and its associated symptoms. A 4 combination of external factors and predispositions are underlying the generation of a 5 migraine attack. The different phases (red circles) have variable length and are characterized 6 by multiple, sometimes overlapping symptoms. The interictal period (green circle) 7 corresponds to the end of migraine-associated symptoms. The duration of this phase is 8 variable and will depend on many factors such as medication overuse or inappropriate 9 behavior leading to a longer exposure to potential triggering factors. As such, chronic migraine patients have a considerably reduced interictal period. 


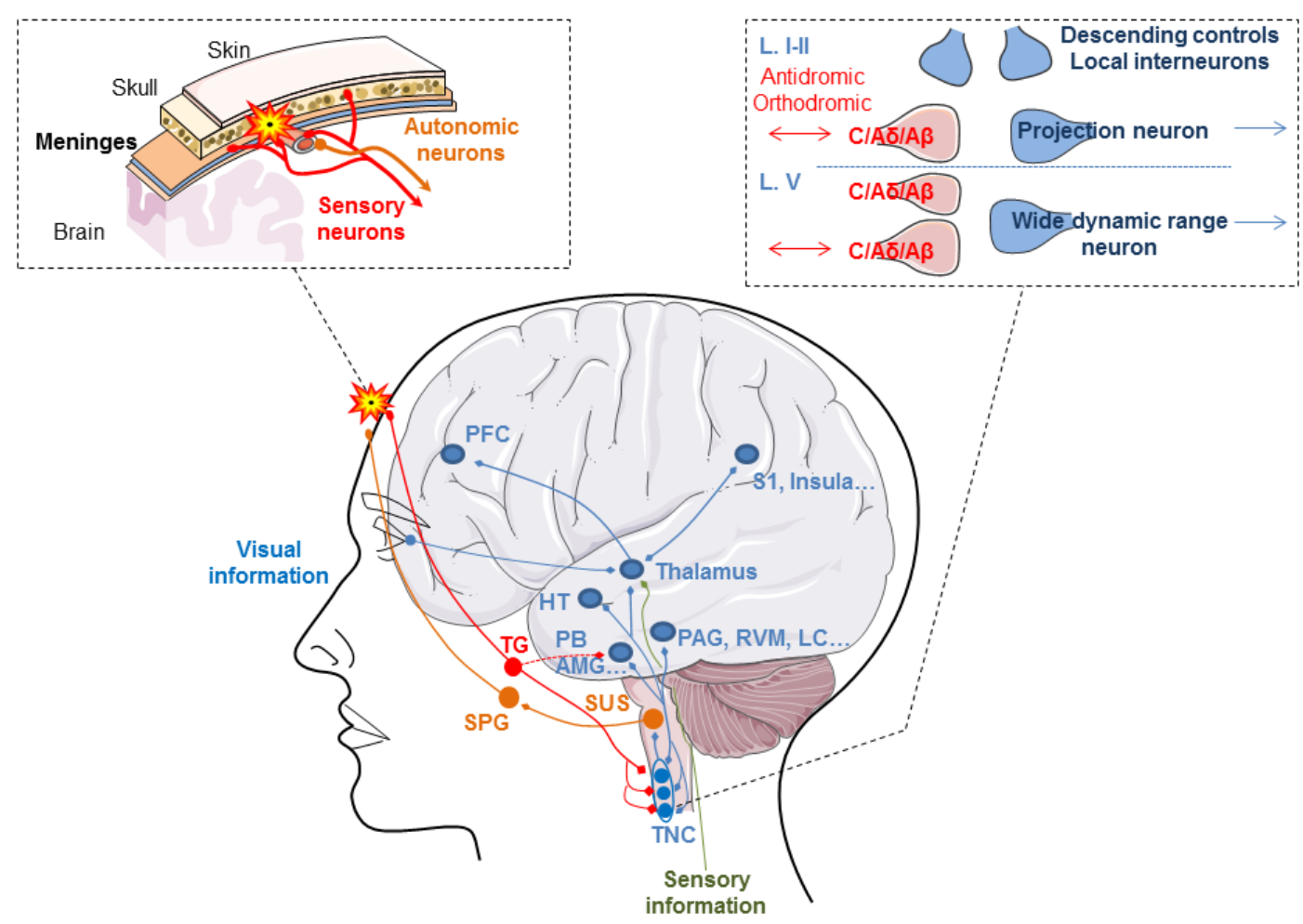

1

2 Figure 2. Migraine pathophysiology: Anatomy of the trigeminovascular pathway. The migraine attack begins in trigeminal ganglion (TG), whose axons (red lines) project to meningeal dura mater blood vessels through the ophthalmic branch stimulating the production of vasoactive neuropeptides. Nociceptive information is then carried from meninges to the rest of the brain though sensory and autonomic neurons. A second group of axons from $T G$ targets the trigeminal nucleus caudalis (TNC), which also receives information from anterior and posterior parts of head and upper neck (red lines). TNC conveys then the inputs to diverse nuclei at limbic system, basal ganglia, hypothalamus, cortex and thalamus (blue lines). The thalamus also integrates stimuli detected from the outside and from internal organs (green lines). Additional nuclei are believed to contribute to migraine headache. Activation of the sphenopalatine ganglion (SPG) (orange lines) may stimulate antidromic sensory fibers converging to the superior salivatory nucleus (SUS), which contains cell bodies involved in the parasympathetic autonomic vasodilator pathway. 


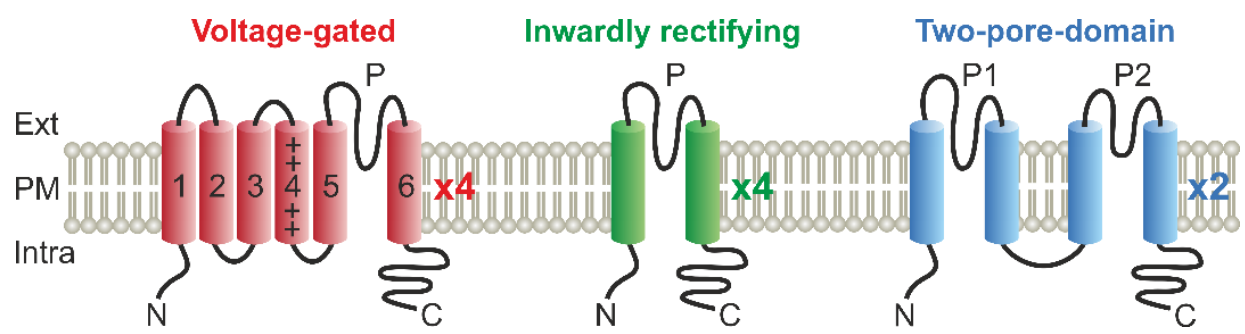

2 Figure 3. Membrane topology of Potassium channels. Voltage-gated channels (red) possess

3 six transmembrane domains and one pore domain $(P)$. Some of them also present a seventh 4 transmembrane segment. The inward rectifier channels (green) consist of two transmembrane 5 domains and one pore domain $(P)$, like the voltage-dependent channels they are active as 6 tetramers. The two-pore-domain potassium channels (blue) possess four transmembrane 7 domains and two pore domains (P1 and P2) and are active as dimers. 


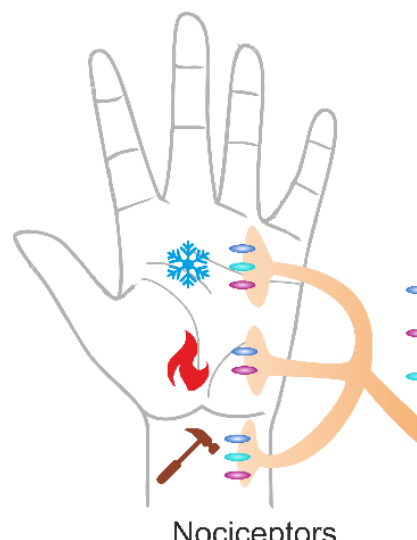

- TREK1

- TREK2

- TRAAK

CENTRAL

SENSITITIZATION

2 Figure 4. TREK channel members are involved in several polymodal ways of pain

3 perception. Thermal and mechanical stimuli are detected by several TREK channels 4 expressed in nociceptors (along with other ASIC, TRP and piezo channels...). They are 5 primary sensors of a nervous signal that is sent to the cortex where it is integrated as a pain 6 signal. DRG for dorsal root ganglion. 
A

Acute migraine induction

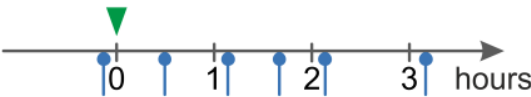

Chronic migraine induction

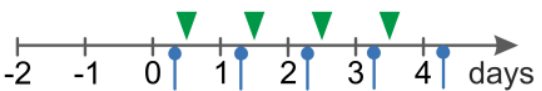

$\nabla$ ISDN injection (10 $\mathrm{mg} / \mathrm{kg}$ or vehicle)

Sensibility test
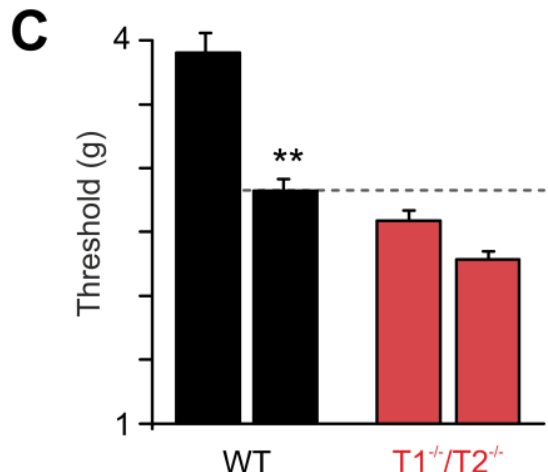

B
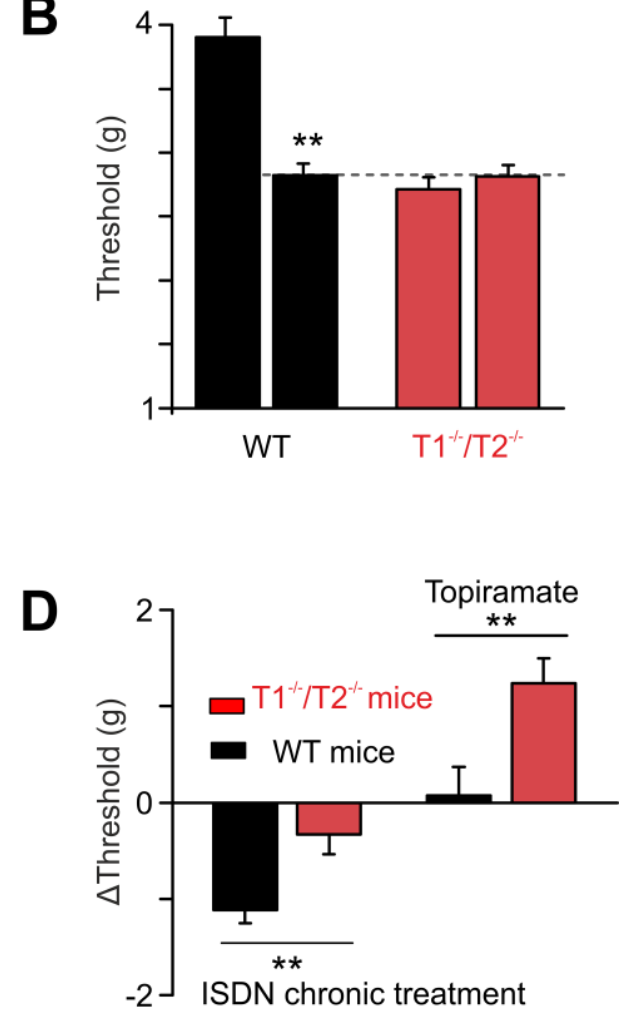

Figure 5. TREK1/-/TREK2 $2^{-/-}$double knockout animals present a migraine-like phenotype. (A) Schematic of experimental behavioral paradigms. Green arrows represent the injection of ISDN, an established migraine trigger. Blue arrows represent measurements of mechanical sensitivity. (B) Bar graph representing the paw withdrawal mechanical thresholds assessed 1.5 hours after ISDN injection. The WT mice present a significant decreased paw withdrawal, whereas no modification was observed for double knockout animals $\left(T 1^{-/} / T^{-/-}\right)$. (C) Mechanical responses, assessed prior to and after chronic ISDN injection (4 days), were significantly decreased in WT animals, whereas no significant change of allodynia was observed in $T 1^{-1} / T 2^{-/}$animals. (D) Variation AThreshold $(\mathrm{g})$ of the paw withdrawal mechanical threshold induced by ISDN chronic treatment or topiramate injection. Mechanical responses were assessed before and after chronic ISDN treatment (4 days, left bars), and before and two hours after topiramate injection (right bars) in ISDN-non treated WT and $T 1^{-1-} / T 2^{-1-}$ mice (from Royal and others 2019). 

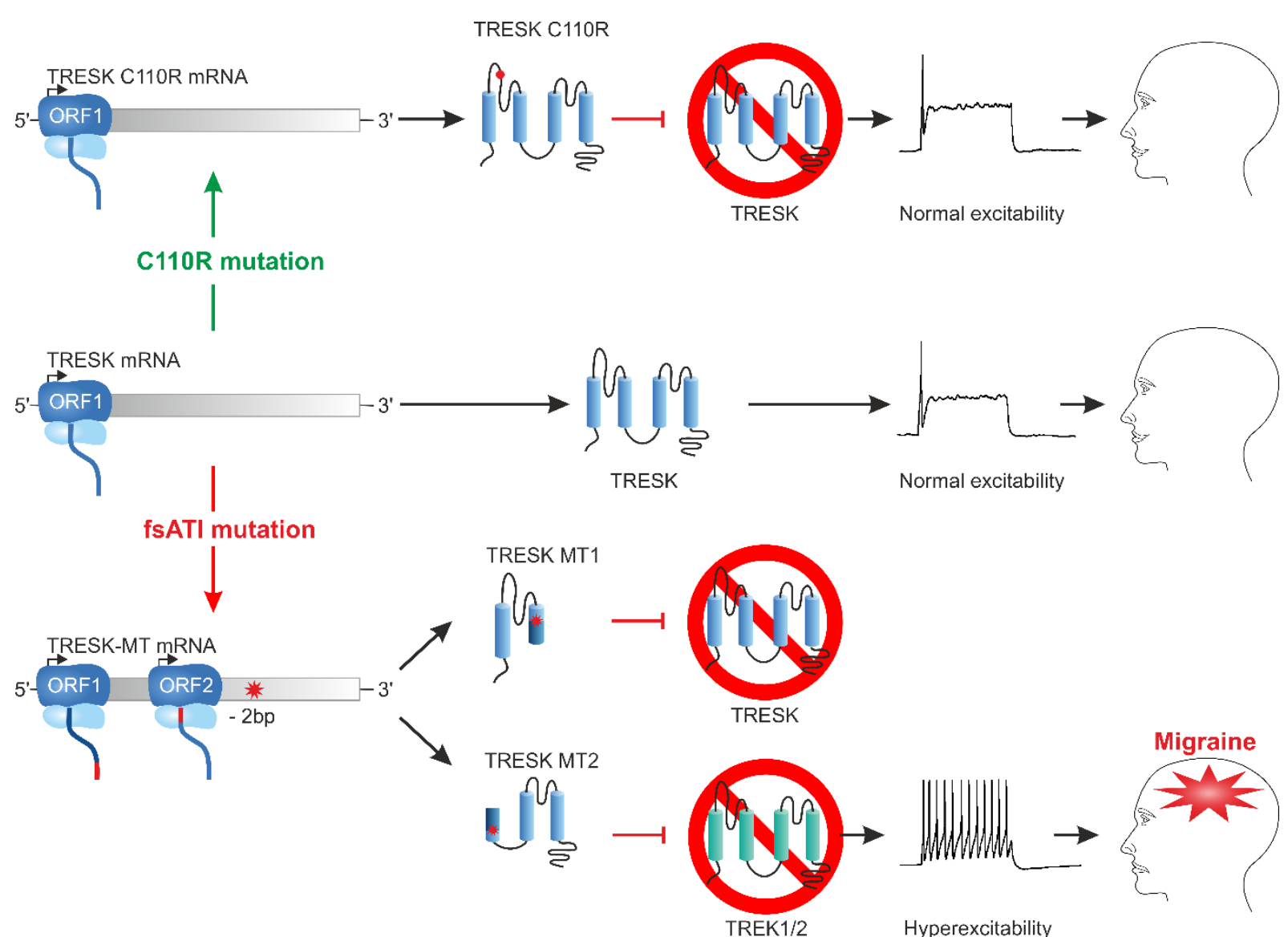

2

3 Figure 6: TRESK-MT causes migraine via inhibition of TREK1 and TREK2 by TRESK-

4 MT2. Top: TRESKC110R targets only TRESK, which is not sufficient to induce an increase of

5 trigeminal sensory neuron excitability and therefore does lead to migraine. Middle: the

6 excitability of trigeminal neurons in the presence of the wild version of TRESK is normal.

7 Bottom: the TRESK-MT mutation generates an ATI (see Boxl) resulting in the formation of

8 two proteins, TRESK-MT1 and TRESK-MT2. TRESK-MT1 inhibits TRESK, while TRESK-

9 MT2 targets TREK1 and TREK2. Inhibition of TREK1 and TREK2 leads to neuronal

10 hyperexcitability causing a migraine phenotype. 


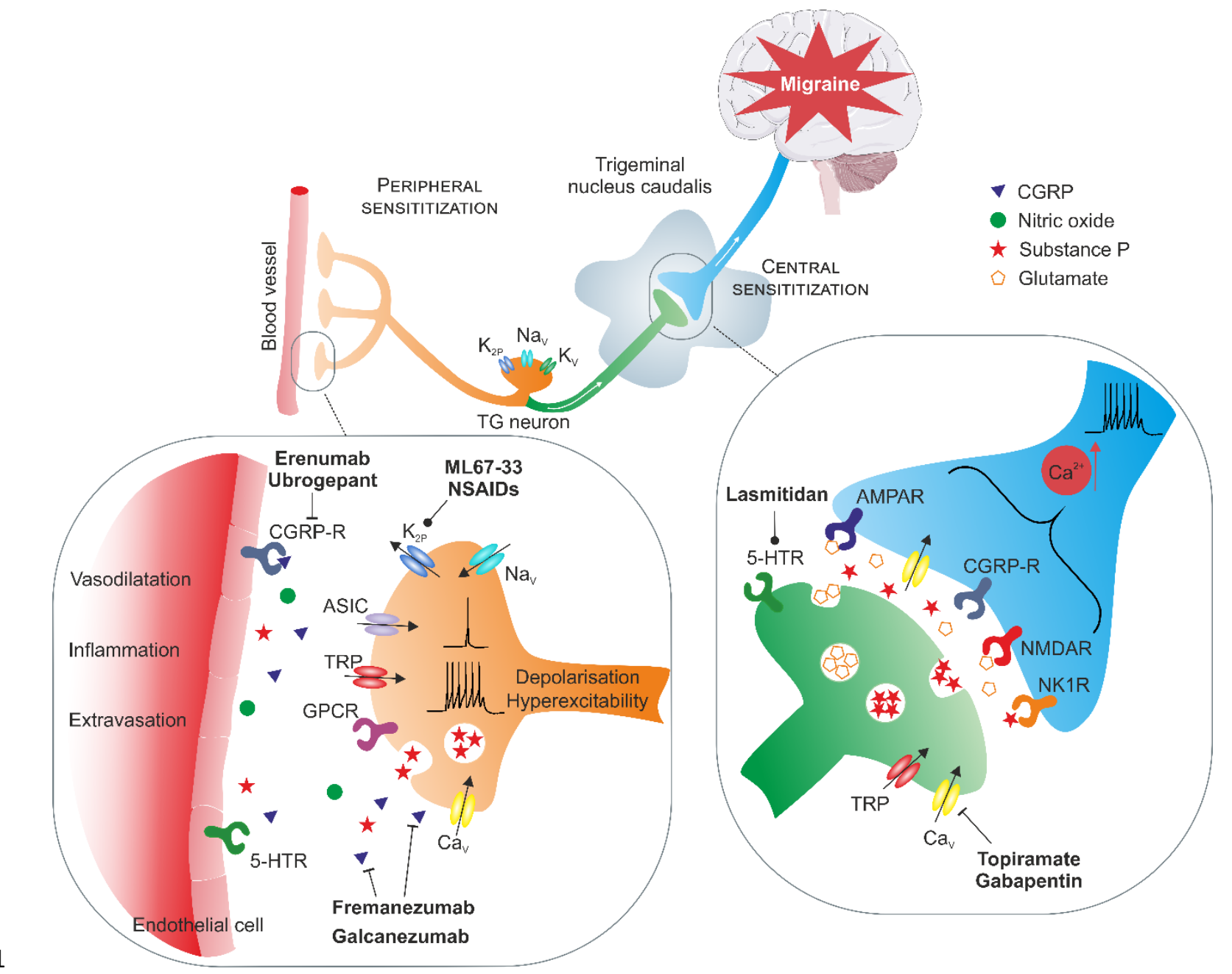

2 Figure 7. Main targets of currently used and potential future drugs for treating migraine

3 headache. The analgesic action is mainly exerted by influencing several classes of receptors

4 (ion channels, GPCRs etc.) at multiple levels of the migraine pain pathway (peripheral

5 trigeminal sensory neurons, TNC second order and higher neurons in the brain). They are

6 principally acting on the neuronal hyperexcitability and the sensitization associated to

7 migraine headache. Multiple drugs will aim at limiting the excessive depolarization through

8 the blockade of inward cation flux (e.g antiepileptics) or, on the opposite, through the

9 activation of hyperpolarizing potassium channels (e.g potential $K_{2 P}$ agonists). Other classes act on the neuronal modulation (e.g CGRP antibodies) or neurotransmitters release (e.g Triptans). 
Acosta C, Djouhri L, Watkins R, Berry C, Bromage K, Lawson SN. 2014. TREK2 expressed selectively in IB4-binding C-fiber nociceptors hyperpolarizes their membrane potentials and limits spontaneous pain. J Neurosci 34(4):1494-509.

Adams AM, Serrano D, Buse DC, Reed ML, Marske V, Fanning KM and others. 2015. The impact of chronic migraine: The Chronic Migraine Epidemiology and Outcomes (CaMEO) Study methods and baseline results. Cephalalgia 35(7):563-78.

Al-Karagholi MA, Hansen JM, Guo S, Olesen J, Ashina M. 2019. Opening of ATP-sensitive potassium channels causes migraine attacks: a new target for the treatment of migraine. Brain 142(9):2644-2654.

Alloui A, Zimmermann K, Mamet J, Duprat F, Noël J, Chemin J and others. 2006. TREK-1, a K+ channel involved in polymodal pain perception. EMBO J 25(11):2368-76.

Andres-Enguix I, Shang L, Stansfeld PJ, Morahan JM, Sansom MS, Lafrenière RG and others. 2012. Functional analysis of missense variants in the TRESK (KCNK18) K channel. Sci Rep 2:237.

Antonova M, Wienecke T, Olesen J, Ashina M. 2013. Prostaglandins in migraine: update. Curr Opin Neurol 26(3):269-75.

Ashina M, Dodick D, Goadsby PJ, Reuter U, Silberstein S, Zhang F and others. 2017. Erenumab (AMG $334)$ in episodic migraine: Interim analysis of an ongoing open-label study. Neurology 89(12):1237-1243.

Ashina M, Hansen JM, Á Dunga BO, Olesen J. 2017. Human models of migraine - short-term pain for long-term gain. Nat Rev Neurol 13(12):713-724.

Ávalos Prado P, Sandoz G. 2019. TREK for High-Speed and High-Frequency Conduction through the Axon. Neuron 104(5):831-833.

Bagriantsev SN, Ang KH, Gallardo-Godoy A, Clark KA, Arkin MR, Renslo AR and others. 2013. A highthroughput functional screen identifies small molecule regulators of temperature- and mechano-sensitive K2P channels. ACS Chem Biol 8(8):1841-51.

Berg AP, Talley EM, Manger JP, Bayliss DA. 2004. Motoneurons express heteromeric TWIK-related acid-sensitive K+ (TASK) channels containing TASK-1 (KCNK3) and TASK-3 (KCNK9) subunits. The Journal of neuroscience : the official journal of the Society for Neuroscience 24(30):66936702.

Bernstein CA, Nir RR, Noseda R, Fulton AB, Huntington S, Lee AJ and others. 2019. The migraine eye: distinct rod-driven retinal pathways' response to dim light challenges the visual cortex hyperexcitability theory. Pain 160(3):569-578.

Blin S, Ben Soussia I, Kim E-J, Brau F, Kang D, Lesage F and others. 2016. Mixing and matching TREK/TRAAK subunits generate heterodimeric $K<$ sub $>2 P</$ sub $>$ channels with unique properties. Proceedings of the National Academy of Sciences 113(15):4200.

Blin S, Chatelain FC, Feliciangeli S, Kang D, Lesage F, Bichet D. 2014. Tandem pore domain halothaneinhibited $\mathrm{K}+$ channel subunits THIK1 and THIK2 assemble and form active channels. The Journal of biological chemistry 289(41):28202-28212.

Bolay H, Reuter U, Dunn AK, Huang Z, Boas DA, Moskowitz MA. 2002. Intrinsic brain activity triggers trigeminal meningeal afferents in a migraine model. Nat Med 8(2):136-42.

Bonnet C, Hao J, Osorio N, Donnet A, Penalba V, Ruel J and others. 2019. Maladaptive activation of Nav1.9 channels by nitric oxide causes triptan-induced medication overuse headache. Nat Commun 10(1):4253.

Borsook D, Maleki N, Becerra L, McEwen B. 2012. Understanding migraine through the lens of maladaptive stress responses: a model disease of allostatic load. Neuron 73(2):219-34.

Bose P, Karsan N, Goadsby PJ. 2018. The Migraine Postdrome. Continuum (Minneap Minn) 24(4, Headache):1023-1031. 
Bree D, Levy D. 2018. Development of CGRP-dependent pain and headache related behaviours in a rat model of concussion: Implications for mechanisms of post-traumatic headache. Cephalalgia 38(2):246-258.

Brohawn SG, Wang W, Handler A, Campbell EB, Schwarz JR, Mackinnon R. 2019. The mechanosensitive ion channel TRAAK is localized to the mammalian node of Ranvier. Elife 8.

Burch RC, Loder S, Loder E, Smitherman TA. 2015. The prevalence and burden of migraine and severe headache in the United States: updated statistics from government health surveillance studies. Headache 55(1):21-34.

Burgos-Vega CC, Ahn DD, Bischoff C, Wang W, Horne D, Wang J and others. 2016. Meningeal transient receptor potential channel M8 activation causes cutaneous facial and hindpaw allodynia in a preclinical rodent model of headache. Cephalalgia 36(2):185-93.

Burstein R, Noseda R, Borsook D. 2015. Migraine: multiple processes, complex pathophysiology. J Neurosci 35(17):6619-29.

Castellanos A, Andres A, Bernal L, Callejo G, Comes N, Gual A and others. 2018. Pyrethroids inhibit K2P channels and activate sensory neurons: basis of insecticide-induced paraesthesias. Pain 159(1):92-105.

Castellanos A, Pujol-Coma A, Andres-Bilbe A, Negm A, Callejo G, Soto D and others. 2020. TRESK background K. J Physiol 598(5):1017-1038.

Charles AC, Baca SM. 2013. Cortical spreading depression and migraine. Nat Rev Neurol 9(11):637-44.

Coppola G, Petolicchio B, Di Renzo A, Tinelli E, Di Lorenzo C, Parisi V and others. 2017. Cerebral gray matter volume in patients with chronic migraine: correlations with clinical features. J Headache Pain 18(1):115.

Coppola G, Vandenheede M, Di Clemente L, Ambrosini A, Fumal A, De Pasqua V and others. 2005. Somatosensory evoked high-frequency oscillations reflecting thalamo-cortical activity are decreased in migraine patients between attacks. Brain 128(Pt 1):98-103.

Czirják G, Enyedi P. 2002. Formation of Functional Heterodimers between the TASK-1 and TASK-3 Two-pore Domain Potassium Channel Subunits. Journal of Biological Chemistry 277(7):54265432.

De Felice M, Ossipov MH, Wang R, Lai J, Chichorro J, Meng I and others. 2010. Triptan-induced latent sensitization: a possible basis for medication overuse headache. Ann Neurol 67(3):325-37.

De Felice M, Porreca F. 2009. Opiate-induced persistent pronociceptive trigeminal neural adaptations: potential relevance to opiate-induced medication overuse headache. Cephalalgia 29(12):1277-84.

De Fusco M, Marconi R, Silvestri L, Atorino L, Rampoldi L, Morgante L and others. 2003. Haploinsufficiency of ATP1A2 encoding the $\mathrm{Na}+\mathrm{K}+$ pump alpha2 subunit associated with familial hemiplegic migraine type 2. Nat Genet 33(2):192-6.

Denuelle M, Fabre N, Payoux P, Chollet F, Geraud G. 2007. Hypothalamic activation in spontaneous migraine attacks. Headache 47(10):1418-26.

Descoeur J, Pereira V, Pizzoccaro A, Francois A, Ling B, Maffre V and others. 2011. Oxaliplatin-induced cold hypersensitivity is due to remodelling of ion channel expression in nociceptors. EMBO Mol Med 3(5):266-78.

Dichgans M, Freilinger T, Eckstein G, Babini E, Lorenz-Depiereux B, Biskup S and others. 2005. Mutation in the neuronal voltage-gated sodium channel SCN1A in familial hemiplegic migraine. Lancet 366(9483):371-7.

Djillani A, Mazella J, Heurteaux C, Borsotto M. 2019. Role of TREK-1 in Health and Disease, Focus on the Central Nervous System. Front Pharmacol 10:379.

Dobler T, Springauf A, Tovornik S, Weber M, Schmitt A, Sedlmeier R and others. 2007. TRESK twopore-domain $\mathrm{K}+$ channels constitute a significant component of background potassium currents in murine dorsal root ganglion neurones. J Physiol 585(Pt 3):867-79.

Domitrz I, Kosiorek M, Żekanowski C, Kamińska A. 2016. Genetic studies of Polish migraine patients: screening for causative mutations in four migraine-associated genes. Hum Genomics 10:3.

Ducros A. 2013. [Genetics of migraine]. Rev Neurol (Paris) 169(5):360-71. 
Edelmayer RM, Vanderah TW, Majuta L, Zhang ET, Fioravanti B, De Felice M and others. 2009. Medullary pain facilitating neurons mediate allodynia in headache-related pain. Ann Neurol 65(2):184-93.

Edvinsson L, Haanes KA, Warfvinge K, Krause DN. 2018. CGRP as the target of new migraine therapies - successful translation from bench to clinic. Nat Rev Neurol 14(6):338-350.

Ferrari U, Empl M, Kim KS, Sostak P, Förderreuther S, Straube A. 2005. Calcineurin inhibitor-induced headache: clinical characteristics and possible mechanisms. Headache 45(3): 211-214.

Frederiksen SD, Haanes KA, Warfvinge K, Edvinsson L. 2019. Perivascular neurotransmitters: Regulation of cerebral blood flow and role in primary headaches. J Cereb Blood Flow Metab 39(4):610-632.

Goadsby PJ, Holland PR, Martins-Oliveira M, Hoffmann J, Schankin C, Akerman S. 2017. Pathophysiology of Migraine: A Disorder of Sensory Processing. Physiol Rev 97(2):553-622.

Gormley P, Anttila V, Winsvold BS, Palta P, Esko T, Pers TH and others. 2016. Meta-analysis of 375,000 individuals identifies 38 susceptibility loci for migraine. Nat Genet 48(8):856-66.

Gormley P, Kurki MI, Hiekkala ME, Veerapen K, Häppölä P, Mitchell AA and others. 2018. Common Variant Burden Contributes to the Familial Aggregation of Migraine in 1,589 Families. Neuron 98(4):743-753.e4.

Gross EC, Klement RJ, Schoenen J, D'Agostino DP, Fischer D. 2019. Potential Protective Mechanisms of Ketone Bodies in Migraine Prevention. Nutrients 11(4).

Guo S, Vollesen AL, Olesen J, Ashina M. 2016. Premonitory and nonheadache symptoms induced by CGRP and PACAP38 in patients with migraine. Pain 157(12):2773-2781.

Guo Z, Liu P, Ren F, Cao YQ. 2014. Nonmigraine-associated TRESK K+ channel variant C110R does not increase the excitability of trigeminal ganglion neurons. J Neurophysiol 112(3):568-79.

Hadjikhani N, Albrecht DS, Mainero C, Ichijo E, Ward N, Granziera C and others. 2020. Extra-axial inflammatory signal in parameninges in migraine with visual aura. Ann Neurol.

Harriott AM, Gold MS. 2009. Contribution of primary afferent channels to neuropathic pain. Curr Pain Headache Rep 13(3):197-207.

Heurteaux C, Lucas G, Guy N, El Yacoubi M, Thümmler S, Peng XD and others. 2006. Deletion of the background potassium channel TREK-1 results in a depression-resistant phenotype. Nat Neurosci 9(9):1134-41.

Honoré E. 2007. The neuronal background K2P channels: focus on TREK1. Nat Rev Neurosci 8(4):25161.

Hwang EM, Kim E, Yarishkin O, Woo DH, Han KS, Park N and others. 2014. A disulphide-linked heterodimer of TWIK-1 and TREK-1 mediates passive conductance in astrocytes. Nat Commun 5:3227.

Jain A, Liu R, Ramani B, Arauz E, Ishitsuka Y, Ragunathan K and others. 2011. Probing cellular protein complexes using single-molecule pull-down. Nature 473(7348):484-8.

Kanda H, Ling J, Tonomura S, Noguchi K, Matalon S, Gu JG. 2019. TREK-1 and TRAAK Are Principal K. Neuron 104(5):960-971.e7.

Karatas H, Erdener SE, Gursoy-Ozdemir Y, Lule S, Eren-Koçak E, Sen ZD and others. 2013. Spreading depression triggers headache by activating neuronal Panx1 channels. Science 339(6123):1092-5.

Karsan N, Goadsby PJ. 2018. Biological insights from the premonitory symptoms of migraine. Nat Rev Neurol 14(12):699-710.

Khan S, Amin FM, Christensen CE, Ghanizada H, Younis S, Olinger ACR and others. 2019. Meningeal contribution to migraine pain: a magnetic resonance angiography study. Brain 142(1):93-102.

Kochetov AV. 2008. Alternative translation start sites and hidden coding potential of eukaryotic mRNAs. BioEssays 30(7):683-691.

Kozak M. 1987. An analysis of 5'-noncoding sequences from 699 vertebrate messenger RNAs. Nucleic Acids Research 15(20):8125-8148.

Kozak M. 1999. Initiation of translation in prokaryotes and eukaryotes. Gene 234(2):187-208. 
Kunkler PE, Zhang L, Johnson PL, Oxford GS, Hurley JH. 2018. Induction of chronic migraine phenotypes in a rat model after environmental irritant exposure. Pain 159(3):540-549.

Lafrenière RG, Cader MZ, Poulin JF, Andres-Enguix I, Simoneau M, Gupta N and others. 2010. A dominant-negative mutation in the TRESK potassium channel is linked to familial migraine with aura. Nat Med 16(10):1157-60.

Levitz J, Royal P, Comoglio Y, Wdziekonski B, Schaub S, Clemens DM and others. 2016. Heterodimerization within the TREK channel subfamily produces a diverse family of highly regulated potassium channels. Proceedings of the National Academy of Sciences 113(15):4194.

Levy D, Labastida-Ramirez A, MaassenVanDenBrink A. 2019. Current understanding of meningeal and cerebral vascular function underlying migraine headache. Cephalalgia 39(13):1606-1622.

Li XY, Toyoda H. 2015. Role of leak potassium channels in pain signaling. Brain Res Bull 119(Pt A):739.

Liu P, Xiao Z, Ren F, Guo Z, Chen Z, Zhao H and others. 2013. Functional analysis of a migraineassociated TRESK K+ channel mutation. J Neurosci 33(31):12810-24.

Mi Hwang E, Kim E, Yarishkin O, Ho Woo D, Han K-S, Park N and others. 2014. A disulphide-linked heterodimer of TWIK-1 and TREK-1 mediates passive conductance in astrocytes. Nature Communications 5(1):3227.

Morenilla-Palao C, Luis E, Fernández-Peña C, Quintero E, Weaver JL, Bayliss DA and others. 2014. Ion channel profile of TRPM8 cold receptors reveals a role of TASK-3 potassium channels in thermosensation. Cell Rep 8(5):1571-82.

Nahman-Averbuch H, Leon E, Hunter BM, Ding L, Hershey AD, Powers SW and others. 2019. Increased pain sensitivity but normal pain modulation in adolescents with migraine. Pain 160(5):1019-1028.

Noseda R, Constandil L, Bourgeais L, Chalus M, Villanueva L. 2010. Changes of meningeal excitability mediated by corticotrigeminal networks: a link for the endogenous modulation of migraine pain. J Neurosci 30(43):14420-9.

Noël J, Zimmermann K, Busserolles J, Deval E, Alloui A, Diochot $S$ and others. 2009. The mechanoactivated K+ channels TRAAK and TREK-1 control both warm and cold perception. EMBO J 28(9):1308-18.

Nyholt DR, Borsook D, Griffiths LR. 2017. Migrainomics - identifying brain and genetic markers of migraine. Nat Rev Neurol 13(12):725-741.

Nyholt DR, LaForge KS, Kallela M, Alakurtti K, Anttila V, Färkkilä M and others. 2008. A high-density association screen of 155 ion transport genes for involvement with common migraine. Hum Mol Genet 17(21):3318-31.

Olesen J, Ashina M. 2015. Can nitric oxide induce migraine in normal individuals? Cephalalgia 35(12):1125-9.

Olesen J, Burstein R, Ashina M, Tfelt-Hansen P. 2009. Origin of pain in migraine: evidence for peripheral sensitisation. Lancet Neurol 8(7):679-90.

Pereira V, Busserolles J, Christin M, Devilliers M, Poupon L, Legha W and others. 2014. Role of the TREK2 potassium channel in cold and warm thermosensation and in pain perception. Pain 155(12):2534-44.

Pettingill P, Weir GA, Wei T, Wu Y, Flower G, Lalic T and others. 2019. A causal role for TRESK loss of function in migraine mechanisms. Brain 142(12):3852-3867.

Plant LD. 2012. A Role for K2P Channels in the Operation of Somatosensory Nociceptors. Front Mol Neurosci 5:21.

Plant LD, Zuniga L, Araki D, Marks JD, Goldstein SAN. 2012. SUMOylation Silences Heterodimeric TASK Potassium Channels Containing K2P1 Subunits in Cerebellar Granule Neurons. Science Signaling 5(251):ra84-ra84.

Rainero I, Rubino E, Gallone S, Zavarise P, Carli D, Boschi S and others. 2014. KCNK18 (TRESK) genetic variants in Italian patients with migraine. Headache 54(9):1515-22. 
Royal P, Andres-Bilbe A, Ávalos Prado P, Verkest C, Wdziekonski B, Schaub S and others. 2019. Migraine-Associated TRESK Mutations Increase Neuronal Excitability through Alternative Translation Initiation and Inhibition of TREK. Neuron 101(2):232-245.e6.

Rua R, McGavern DB. 2018. Advances in Meningeal Immunity. Trends Mol Med 24(6):542-559.

Schulte LH, May A. 2016. Functional Neuroimaging in Migraine: Chances and Challenges. Headache 56(9):1474-1481.

Schytz HW, Wienecke T, Olesen J, Ashina M. 2010. Carbachol induces headache, but not migraine-like attacks, in patients with migraine without aura. Cephalalgia 30(3):337-45.

Sheftell F, Rapoport A, Weeks R, Walker B, Gammerman I, Baskin S. 2000. Montelukast in the prophylaxis of migraine: a potential role for leukotriene modifiers. Headache 40(2):158-63.

Spindler BL, Ryan M. 2020. Recent Medications Approved for Preventing Migraine Headaches. Am J Med.

Strassman AM, Raymond SA, Burstein R. 1996. Sensitization of meningeal sensory neurons and the origin of headaches. Nature 384(6609):560-4.

Suzuki Y, Tsutsumi K, Miyamoto T, Yamamura H, Imaizumi Y. 2017. Heterodimerization of two pore domain $\mathrm{K}+$ channel TASK1 and TALK2 in living heterologous expression systems. PLOS ONE 12(10):e0186252.

Thomas D, Plant LD, Wilkens CM, McCrossan ZA, Goldstein SA. 2008. Alternative translation initiation in rat brain yields K2P2.1 potassium channels permeable to sodium. Neuron 58(6):859-70.

Turner DP, Houle TT. 2018. Influences on headache trigger beliefs and perceptions. Cephalalgia 38(9):1545-1553.

Uddman R, Edvinsson L, Ekman R, Kingman T, McCulloch J. 1985. Innervation of the feline cerebral vasculature by nerve fibers containing calcitonin gene-related peptide: trigeminal origin and co-existence with substance P. Neurosci Lett 62(1):131-6.

van den Maagdenberg AM, Pietrobon D, Pizzorusso T, Kaja S, Broos LA, Cesetti T and others. 2004. A Cacna1a knockin migraine mouse model with increased susceptibility to cortical spreading depression. Neuron 41(5):701-10.

van Dongen RM, Zielman R, Noga M, Dekkers OM, Hankemeier T, van den Maagdenberg AM and others. 2017. Migraine biomarkers in cerebrospinal fluid: A systematic review and metaanalysis. Cephalalgia 37(1):49-63.

Vila-Pueyo M. 2018. Targeted 5-HT. Neurotherapeutics 15(2):291-303.

Vila-Pueyo M, Hoffmann J, Romero-Reyes M, Akerman S. 2019. Brain structure and function related to headache: Brainstem structure and function in headache. Cephalalgia 39(13):1635-1660.

Wright PD, McCoull D, Walsh Y, Large JM, Hadrys BW, Gaurilcikaite E and others. 2019. Pranlukast is a novel small molecule activator of the two-pore domain potassium channel TREK2. Biochem Biophys Res Commun 520(1):35-40.

Yamamoto Y, Hatakeyama T, Taniguchi K. 2009. Immunohistochemical colocalization of TREK-1, TREK-2 and TRAAK with TRP channels in the trigeminal ganglion cells. Neurosci Lett 454(2):129-33.

Zerimech S, Chever O, Scalmani P, Pizzamiglio L, Duprat F, Mantegazza M. 2020. Cholinergic modulation inhibits cortical spreading depression in mouse neocortex through activation of muscarinic receptors and decreased excitatory/inhibitory drive. Neuropharmacology 166:107951. 